\title{
Ohmic contacts fabricated on moderately doped p-type GaAs by sputtering deposition and a laser-firing process
}

\author{
Alfredo Boronat, ${ }^{\text {a) }}$ Santiago Silvestre, and Albert Orpella \\ MNT_Electronic Engineering Department, Universitat Politècnica de Catalunya, C/ Jordi Girona 1-3, \\ Campus Nord UPC, 08034 Barcelona, Spain
}

(Received 1 February 2013; accepted 27 August 2013; published 12 September 2013)

A novel approach is used to achieve ohmic contacts on moderately doped p-type GaAs substrates. A laser-firing process is used instead of the conventional annealing step. The morphology of the crater created by the laser-firing process and the electrical response of the metal-semiconductor contact are characterized. ( 2013 American Vacuum Society. [http://dx.doi.org/10.1116/1.4820912]

\section{INTRODUCTION}

When the potential voltage drop across a metal-semiconductor contact is linearly related to the current, the contact is said to be ohmic, and the contact resistance $R_{C}$ is the slope of the voltage-current characteristic. The contact voltage drop depends on the specific contact resistivity $\left(\rho_{\text {cef }}\right)$, the dimensions of the contact area, and the level of electrical current. Two main approaches are used to achieve low $\rho_{\text {cef }}$ values on low doped III-V semiconductors: ${ }^{1,2}$ (1) creation of a heavily doped layer under the contact area in the semiconductor, and (2) formation of a lower bandgap semiconductor region at the contact interface.

The low barrier heights $\left(\varnothing_{\mathrm{B}} \sim 0.5 \mathrm{eV}\right)$ of p-type materials and the potential to achieve sufficiently high doping levels allow the formation of ohmic contacts on p-type GaAs. Aubased alloys are the materials most commonly used for both n- and p-type $\mathrm{GaAs},{ }^{3}$ with $\mathrm{Au} / \mathrm{Zn} / \mathrm{Au},{ }^{4,5} \mathrm{AuBe},{ }^{6}$ and Ti/Pt/ $\mathrm{Au}$ (Ref. 6) contacts being the most common on p-type GaAs. In most cases, high temperature thermal steps are necessary. However, low temperature processes are required in the fabrication of some electronic devices, including: solar cells, where the use of low temperature processes helps to prevent device degradation; ${ }^{7,8}$ new structures related to the Intermediate Band concept, where low temperature is essential to achieve sufficient $\mathrm{Ti}$ concentrations; ${ }^{9}$ or in applications based on the integration of GaAs films on Si substrates, where thermal stress is an important issue. ${ }^{10}$

In this work, alloyed contacts were fabricated on III-V substrates using a technique in which only a localized region is heated to avoid thermal stresses on the whole structure. Ohmic contacts were fabricated on moderately doped p-type GaAs substrate wafers by sputtering deposition of $\mathrm{Au} / \mathrm{Zn} / \mathrm{Au}$ structures followed by the use of a laser-firing process whereby a pulsed laser beam drives the $\mathrm{Zn}$ into the GaAs but also forms a small crater-like structure. Laser fired contacts (LFC) have been successfully applied in other studies to form ohmic contacts. ${ }^{11-13}$

This work is divided in two stages. In the first stage, we investigated how $\mathrm{Zn}$ sputtering power conditions influence the electrical characteristics of metal-semiconductor contacts. This stage concluded by using a rapid thermal annealing

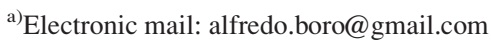

(RTA) step extracting the substrate resistivity. In the second stage, we analyzed different laser-firing parameters to determine optimal values, taking into account the electrical characteristics of the metal-semiconductor contact and the morphology of the crater created.

\section{EXPERIMENTAL METHODS}

For substrates, we used commercial (LEC) p-type GaAs single sided polished wafers with $625 \mu \mathrm{m}$ thickness and $\mathrm{Zn}$ doped concentration of $\sim 10^{17} \mathrm{~cm}^{-3}$. All metal layers were deposited using an RF Sputtering System ESM100 Edwards \& RFS5 Generator-300 W. Zn targets were presputtered for $45 \mathrm{~min}$ to clean them prior to each $\mathrm{Zn}$ layers deposition. All films were deposited under a constant $10 \mathrm{sccm}$ flux of pure Ar. The total working pressure was kept at $0.2 \mathrm{~Pa}$ for $\mathrm{Zn}$ layer and at $0.5 \mathrm{~Pa}$ for $\mathrm{Au}$ layers. The base vacuum of the sputtering chamber before each deposition was less than $9 \times 10^{-4}$ $\mathrm{Pa}$ for all processes. A thermocouple was placed next to the sample exposed to direct impact of sputtered atoms in order to monitor the temperature during the sputtering process.

In this work, the ohmic contacts were fabricated using a multilayer structure of $\mathrm{Au} / \mathrm{Zn} / \mathrm{Au}(20 \mathrm{~nm} / 50 \mathrm{~nm} / 250 \mathrm{~nm})$ layer thicknesses were selected based on previous literature. ${ }^{4,5}$ The first $\mathrm{Au}(20 \mathrm{~nm})$ layer is designed to provide good adhesion of the $\mathrm{Zn}$ layer and its relative thinness should permit easy penetration of $\mathrm{Zn}$ into the GaAs bulk during the alloy process. The $\mathrm{Zn}(50 \mathrm{~nm})$ layer is the doping source to create the tunneling ohmic contact. The last $\mathrm{Au}(250 \mathrm{~nm})$ layer prevents vaporization of $\mathrm{Zn}$ during the thermal step process.

The substrate was cut into $2 \mathrm{~cm} \times 2 \mathrm{~cm}$ pieces to allow multiple experiments. After cutting, the samples were cleaned in an ultrasonic acetone bath followed by an ultrasonic isopropanol bath to remove any dust deposited during the cutting process.

Figure 1 shows the vertical structure used to evaluate the electrical behavior of the metal-semiconductor contact. First, the unpolished side was covered with the multilayer structure to create a large back contact. Then, round contacts were deposited on the polished side of the substrate. The round contacts were defined by using a shadow mask in order to avoid the need for a lithography step, which typically requires temperatures above $100{ }^{\circ} \mathrm{C}$ that could alter the interface either by resin waste or developer reactivity. 


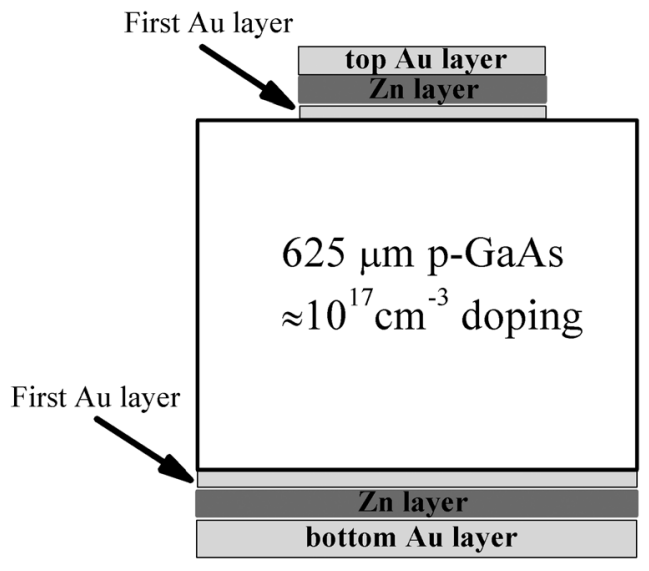

FIG. 1. Schematic cross sections of samples.

The laser system used to carry out this work was a Q-switched Nd:YAG laser (StarMark SMP 100II RofinBaassel; Stanberg, Germany), operating at a wavelength of $1064 \mathrm{~nm}$ in $\mathrm{TEM}_{00}$ mode with a $100 \mathrm{~ns}$ pulse duration. The laser power can be adjusted from 0.8 to $6.4 \mathrm{~W}$ by varying the pump lamp current (software control parameter). The laser power was measured using a power thermal sensor [OPHIR 30 (150)A-BB-18].

\section{RESULTS AND DISCUSSION}

\section{A. Effect of the RF sputtering power deposition of the $\mathrm{Zn}$ layer}

The first stage of this study is focused on selecting favorable RF sputtering conditions, for the different layers especially power and deposition times. A maximum substrate temperature of $50{ }^{\circ} \mathrm{C}$ was selected to ensure a low temperature process. It is widely reported that RF power has a direct influence on the energy of atoms sputtered from the target impinging on the substrate. ${ }^{14}$ This energy and the deposition time affect the temperature reached by the substrate. The deposition conditions of $\mathrm{Au}$ layers for substrate temperatures below $50{ }^{\circ} \mathrm{C}$ are detailed in Table I.

The possibility of a $\mathrm{Zn}$ diffusion by increasing the RF sputtering power was explored to assess whether increasing RF sputtering power can lead to ohmic contact formation. Powers of 25,50 , and $75 \mathrm{~W}$ were used. The low power $(25 \mathrm{~W})$ is the minimum power that sputters atoms from the $\mathrm{Zn}$ target in our equipment, and the high power $(75 \mathrm{~W})$ was established to avoid problems with the reflected sputtering power. The thickness of the $\mathrm{Zn}$ layer was fixed at $50 \mathrm{~nm}$, based on previous studies. ${ }^{4,5}$ Sputtering conditions for each sample are summarized in Table II.

TABLE I. Sputtering conditions for deposition of Au layers.

\begin{tabular}{lcccc}
\hline \hline Layer & $\begin{array}{c}\text { Power } \\
(\mathrm{W})\end{array}$ & $\begin{array}{c}\text { Thickness } \\
(\mathrm{nm})\end{array}$ & $\begin{array}{c}\text { Deposition } \\
\text { time }(\mathrm{min})\end{array}$ & $\begin{array}{c}\text { Substrate } \\
\text { temperature }\left({ }^{\circ} \mathrm{C}\right)\end{array}$ \\
\hline First Au layer & 15 & 20 & 10 & 38 \\
Top Au layer & 25 & 250 & 40 & 50 \\
\hline \hline
\end{tabular}

TABLE II. Sputtering conditions for deposition of Zn layers.

\begin{tabular}{lcccc}
\hline \hline Sample & $\begin{array}{c}\text { Power } \\
(\mathrm{W})\end{array}$ & $\begin{array}{c}\text { Thickness } \\
(\mathrm{nm})\end{array}$ & $\begin{array}{c}\text { Deposition } \\
\text { time }(\mathrm{s})\end{array}$ & $\begin{array}{c}\text { Substrate } \\
\text { temperature }\left({ }^{\circ} \mathrm{C}\right)\end{array}$ \\
\hline $\mathrm{A}$ & 25 & 50 & 150 & 36 \\
$\mathrm{~B}$ & 50 & 50 & 60 & 43 \\
$\mathrm{C}$ & 75 & 50 & 40 & 49 \\
$\mathrm{D}^{\mathrm{a}}$ & 75 & 50 & 40 & 49 \\
\hline \hline
\end{tabular}

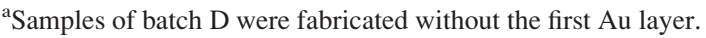

The fabrication process was conducted as follows:

(1) Cleaning step: The samples were cut and then cleaned in an ultrasonic bath of acetone followed by an isopropanol ultrasonic bath and dried by $\mathrm{N}_{2}$ blowing.

(2) Back contact deposition: A metallic multilayer $\mathrm{Au} / \mathrm{Zn} /$ Au structure $(20 \mathrm{~nm} / 50 \mathrm{~nm} / 250 \mathrm{~nm})$ was deposited on the rough side of the substrate.

(3) Front contact deposition: Front round contacts, with the same metallic multilayer used in the back contact, were defined on the polished side of the samples by using a shadow mask. At this point, the I-V characteristics of the samples were measured. Results are shown in Fig. 2, where it is evident that the total resistance decreases as the RF sputtering power is increased. However, a clear rectifying behavior still remains in all the samples.An additional batch of samples (D) was fabricated without the first $\mathrm{Au}$ layer. The $\mathrm{Zn}$ layer was deposited at $75 \mathrm{~W}$ for this batch. The results were similar to those obtained for batch $\mathrm{C}$. However, this experiment reveals that sputtering a $\mathrm{Zn}(50 \mathrm{~nm}) / \mathrm{Au}(200 \mathrm{~nm})$ structure does not present any adhesion problems.Finally, in order to extract the resistivity of the substrates, an additional step was required to form an ohmic contact on each sample using a conventional process. Figure 3(a) shows a top view of the samples described in this section. Front round contacts of five different sizes were defined.

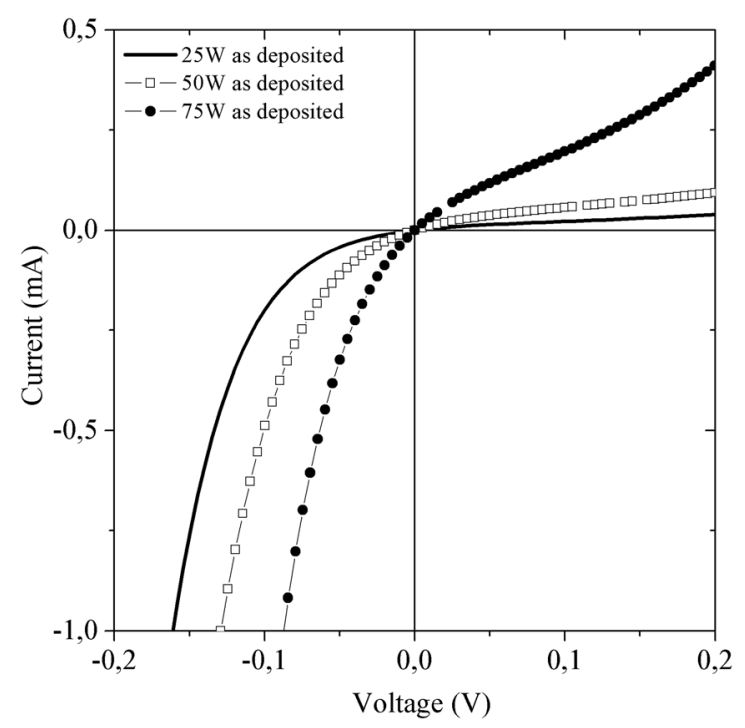

FIG. 2. I-V responses as a function of the $\mathrm{Zn}$ RF sputtering power. 


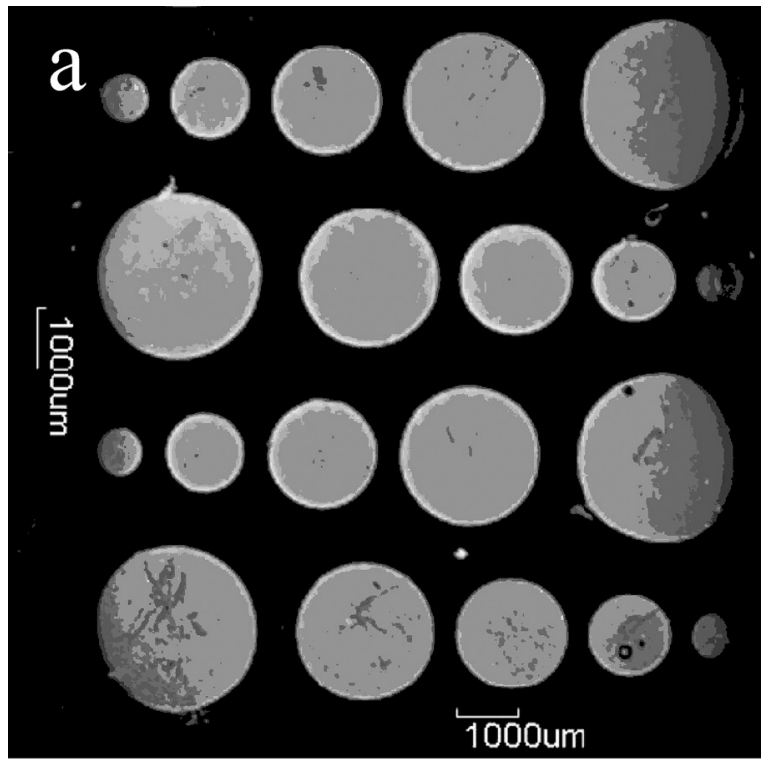

b

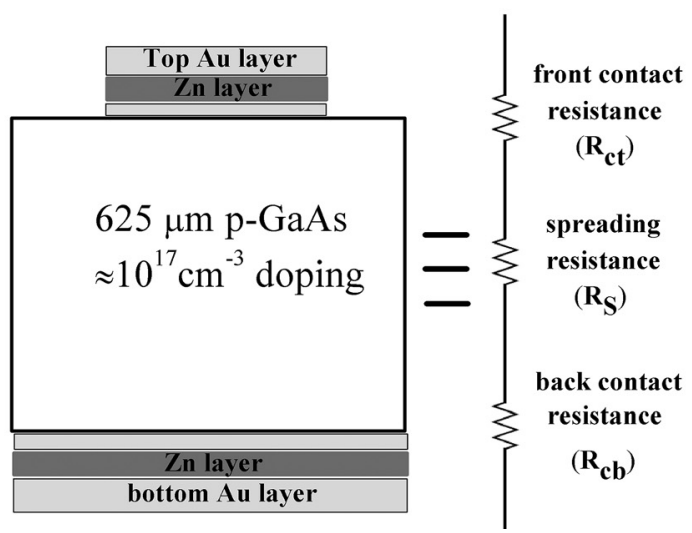

FIG. 3. (a) Top view of samples used in Sec. III A. (b) Equivalent resistance of the structure after RTA step.

(4) Rapid thermal annealing: This step was performed based on the conditions reported in a previous work. ${ }^{4}$ Figure 3(b) shows the equivalent resistance of a structure after the RTA step. The total resistance can be calculated using the following equation:

$R_{T}=R_{S}+R_{c t}+R_{c b}$

where $R_{S}$ is the resistance corresponding to the bulk or spreading resistance, and $R_{c t}$ and $R_{c b}$ are the resistances of the front and back contacts, respectively. The round front contact area is completely defined, but the back contact area is unknown. Therefore, we decided to consider the worst case as $R_{c b}=R_{c t}$, when in fact $R_{c b}<R_{c t}$, which leads to

$R_{T} \cong R_{S}+2 R_{c t}$.

The expression below was chosen to calculate the spreading resistance, based on a previous analytical study ${ }^{15}$
$R_{S}=\frac{\rho_{b}}{2 \pi r} \arctan \left(\frac{2 W}{r}\right)$

where $\rho_{b}$ is the substrate resistivity, $r$ is the radius of the front round contact, and $W$ is the distance between the front and the back contact, i.e., the thickness of the wafer.

By adjusting Eq. (2) with the curve obtained from the relation between the total resistance $R_{T}(r)$ and the front contact area, a substrate resistivity value of approximately $0.1 \pm 0.03 \Omega \mathrm{cm}$ was obtained. This fitting is only minimally affected by the approximation used in Eq. (2), because of the structure characteristics (radius $r$ between 0.05 and $0.15 \mathrm{~cm}$, thickness of $625 \mu \mathrm{m}$, and specific contact resistivity less than $10^{-4} \Omega \mathrm{cm}^{2}$ reported in previous works for this contact). ${ }^{4,5}$ Thus, the contact resistance term only represents approximately $3 \%$ of the total measured resistance.

\section{B. Laser firing process study}

In this section, the influence of laser-firing parameters on the electrical behavior of the metal-semiconductor contact and the morphology of the resulting crater (the disturbance to the contact topology produced by the laser heating) are analyzed. The fabrication process sequence varies from that detailed in Sec. III A. First, an ohmic contact was formed on the rough side of the sample using the conventional procedure of depositing the metallic multi-layer structure followed by a RTA step. Next, round front contacts with a radius of $1.25 \mathrm{~mm}$ were defined on the polished side by using a shadow mask [Fig. 4(a)]. Thus, the influence of the laser process was evaluated for an ohmic contact deposited on the back side of the sample and the as-deposited front side of the vertical structure. Figure 4(b) shows the equivalent electrical circuit of the structure before and after the laser-firing process.

The key parameters examined in the laser process were power (related to the energy of the beam), number of pulses (which can be interpreted as the duration of the thermal step), and pitch (distance between points of laser-firing contact).

\section{Influence of the laser-firing power}

The influence of the laser beam power was analyzed keeping the number of laser pulses (Np) fixed at 62 pulses. The laser power was varied in the range of $0.8-6.4 \mathrm{~W}$. In our system, the minimum power that forms an ohmic contact is $1.7 \mathrm{~W}$. The heating produced by the laser pulses at this power appears to be sufficient to drive $\mathrm{Zn}$ atoms into the GaAs substrate and create an ohmic contact.

Figures 5(a) and 5(b) show the effects of the laser power on total resistance and on radius of the resulting crater. As is visible in Fig. 5(b), the radius of the crater increases monotonically as the power increases. The inset shows the profile defining the typical crater. In contrast, the total resistance presents a minimum at $3.2 \mathrm{~W}$ of laser power. The crater area can be considered the contact area, so based on the relation between crater radius and laser power, we conclude that optimal laser power is in the range of $1.7-3.2 \mathrm{~W}$. 


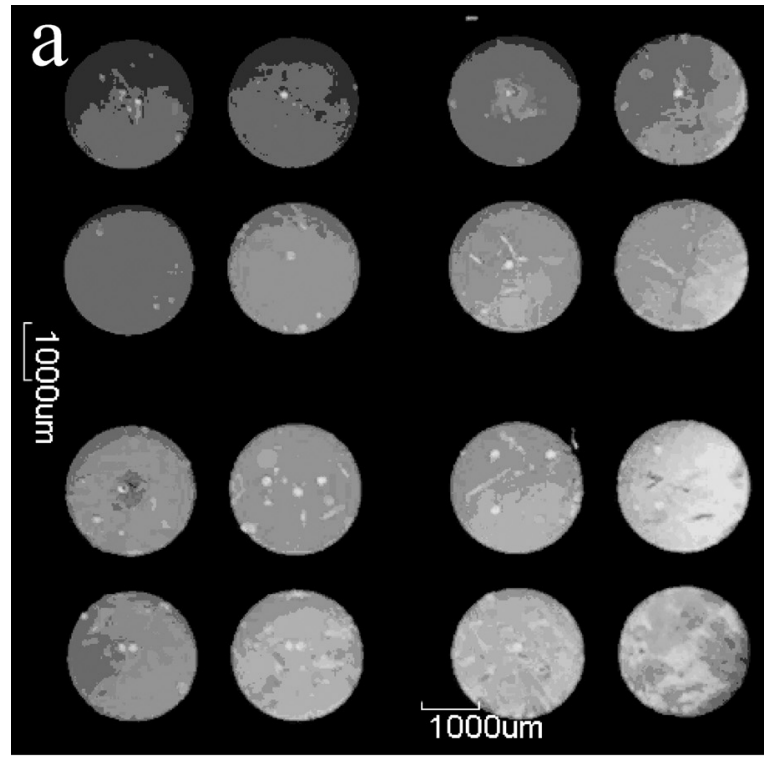

b

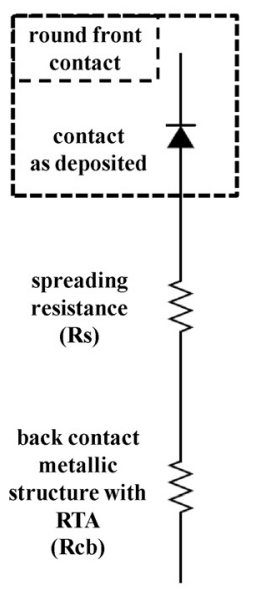

BEFORE LFC PROCESS

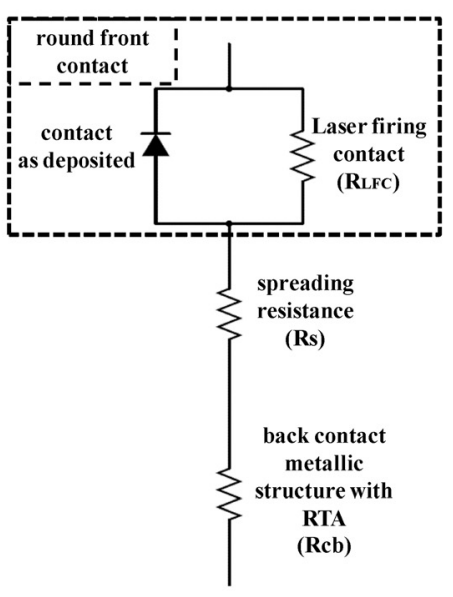

AFTER LFC PROCESS

FIG. 4. (a) Top view of samples used in Sec. III B to carry out the laser process study. (b) Equivalent electrical circuit of samples used in Sec. III B, before and after laser-firing contact process on the front round contact.

In order to extract the specific contact resistivity, the worst case is again considered, supposing that all the contact resistance is due to the top laser-firing contact $R_{L F C}$, including $R_{\mathrm{cb}}$ in $R_{L F C}$. The measured resistance of the vertical structure follows the equation:

$$
R_{\text {measured }}=R_{S}+R_{L F C}
$$

where $R_{S}$ is the spreading resistance. The specific contact resistivity of the laser-firing contact can be evaluated as

$$
\begin{aligned}
& R_{L F C}=\frac{\rho_{c e f_{L F C}}}{\pi r_{L F C}{ }^{2}} \\
& \rho_{c e f_{L F C}}=\pi r_{L F C}{ }^{2}\left[R_{\text {measured }}-\frac{\rho_{b}}{2 \pi r_{L F C}} \arctan \left(\frac{2 W}{r_{L F C}}\right)\right] .
\end{aligned}
$$

The theoretical value of the spreading resistance $R_{S}$, working with the substrate resistivity $\rho_{b}$ extracted from
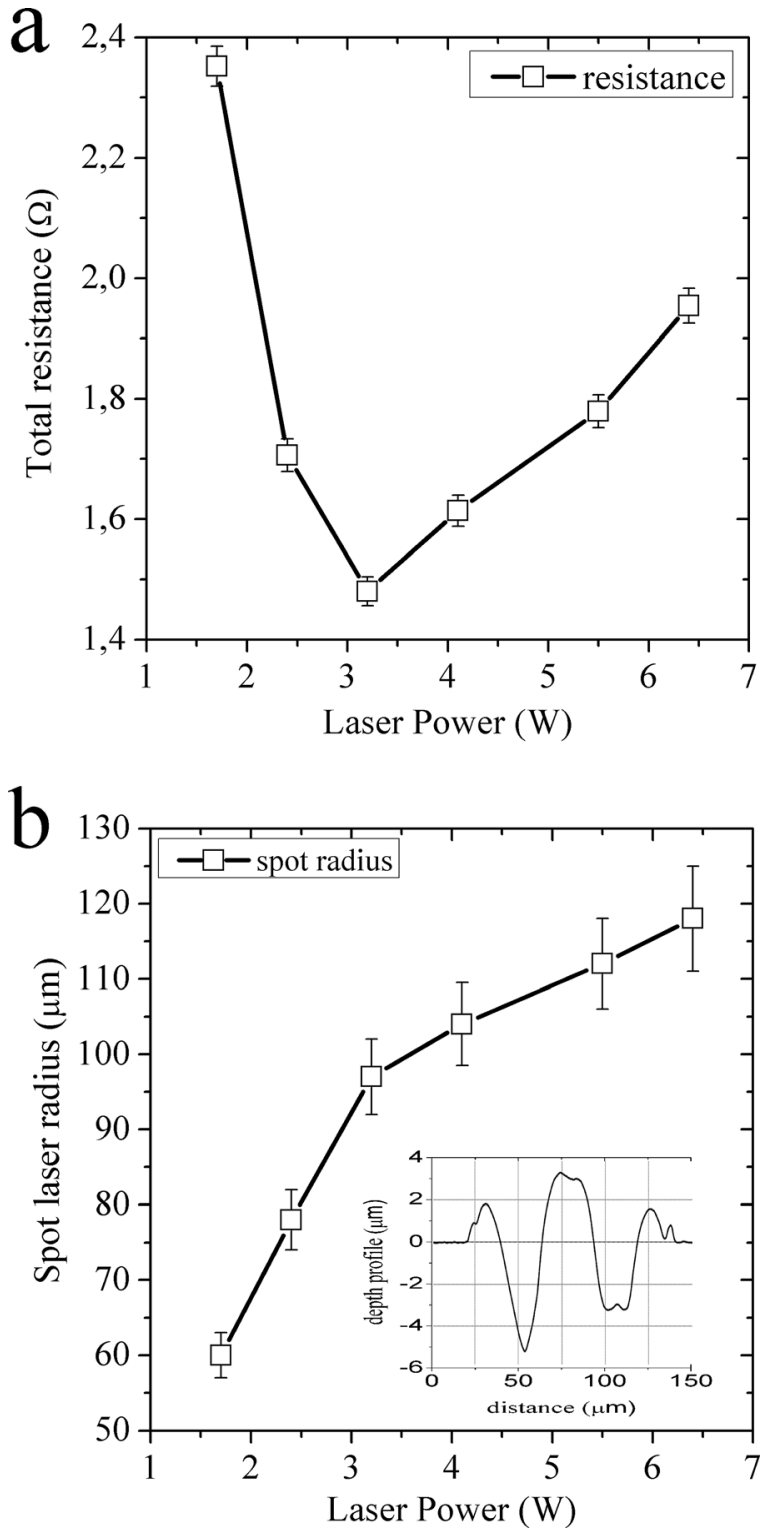

FIG. 5. (a) Effect of laser power on the total measured resistance. (b) Effect of laser power on the radius of the laser crater. The inset in the figure shows a depth profile of the crater created at $1.7 \mathrm{~W}$.

Sec. III A and the radius $r_{L F C}$ of the crater, is greater than the total resistance measured $R_{\text {measured }}$. This inconsistency is due to a contact area larger than the crater area considered, as will be shown in the following sections. Finally, a laser power of $1.7 \mathrm{~W}$ was selected to create shallow craters.

\section{Influence of number of pulses}

The Np parameter can be interpreted as the duration of the thermal process of the laser-firing. The value of $\mathrm{Np}$ has a great influence on the morphology of the spot crater as is evidenced by the SEM images shown in Figs. 6(a) and 6(b). Figure 6(a) shows a detailed view of the crater created by $\mathrm{Np}=251$ pulses, where a relatively smooth surface can be observed. Figure 6(b) shows a general view of the $158 \mu \mathrm{m}$ diameter crater created using $\mathrm{Np}=2000$ pulses with a deep hole in the center. 

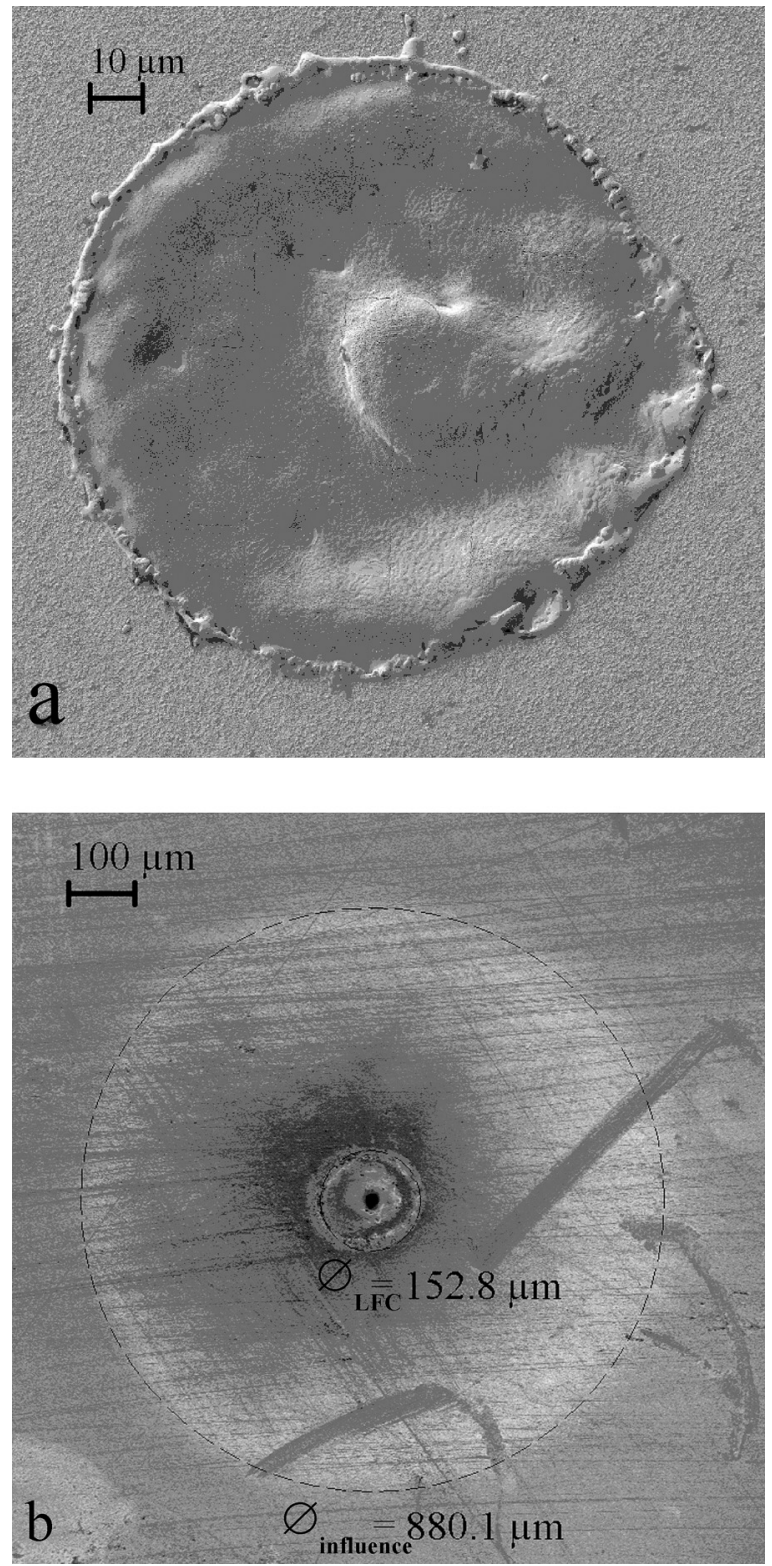

FIG. 6. SEM images: (a) detailed view of the crater using $1.7 \mathrm{~W}$ and $251 \mathrm{~Np}$; (b) general view of the crater using $1.7 \mathrm{~W}$ and $2000 \mathrm{~Np}$

Increasing the $\mathrm{Np}$ value led to an increasing influence by the LFC area, which is manifested by a color change of the area near the crater, as observed with an optical microscope. This effect was also confirmed by SEM [Fig. 6(b)] where a clear topographic contrast in the area of about $880 \mu \mathrm{m}$ of diameter surrounding the crater is mainly due to differences in the material, not topography changes. This circular area of laser influence around the crater is formed by local heating effects that cause an inter-diffusion between substrate and $\mathrm{Au} / \mathrm{Zn} / \mathrm{Au}$ deposited layers. The EDX analysis supports this conclusion.

The increase of $\mathrm{Np}$ also led to an increase in crater radius, as shown in Fig. 7. This effect is greater as the intensity increases, from a $5 \%$ increment of the crater radius at $1.7 \mathrm{~W}$ to $20 \%$ for $3.2 \mathrm{~W}$. It was determined that a minimum of 62 pulses are needed to create the ohmic contact for a power of $1.7 \mathrm{~W}$.

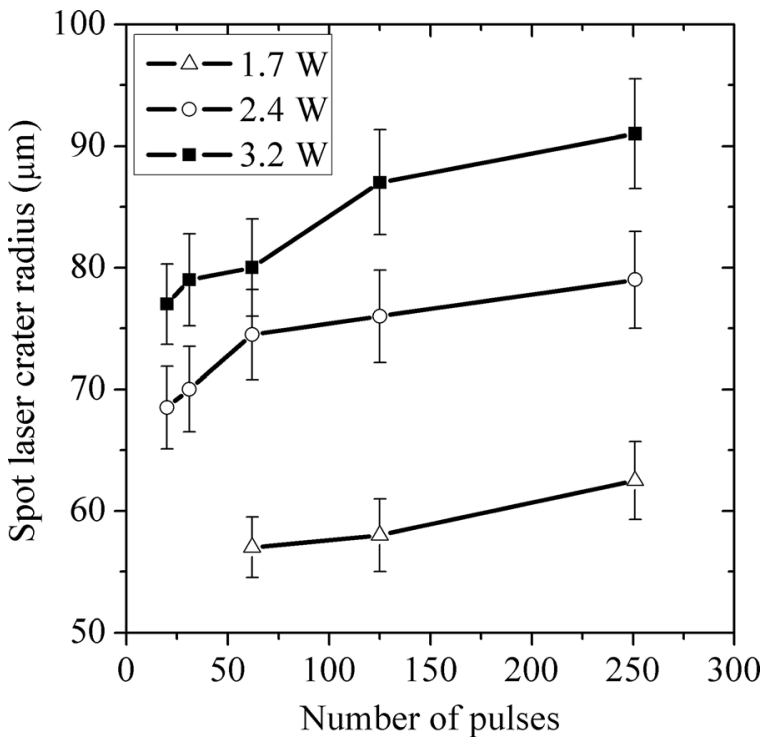

FIG. 7. Influence of the Np parameter on crater radius for three different powers.

Figure 8 shows the influence of $\mathrm{Np}$ on the total resistance. The ability to determine an exact specific contact resistivity value is restricted by the contact area evaluated. The SEM images presented in Fig. 6(b) show that the influence area can be five times greater than the crater, making it difficult to accurately determine the contact area. This fact explains the inconsistency discussed in Sec. III B 1.

\section{Analysis of the laser-firing pitch effect}

The pitch refers to the distance between two different LFC points. The role of the pitch depends on the kind of application. For example, in a previous work ${ }^{11}$ studying ohmic contact formation by laser-firing process, the optimum pitch depends on the tradeoff between the total contact resistance and the deterioration of the passivation. In this work, the study of pitch is related to the premise that the

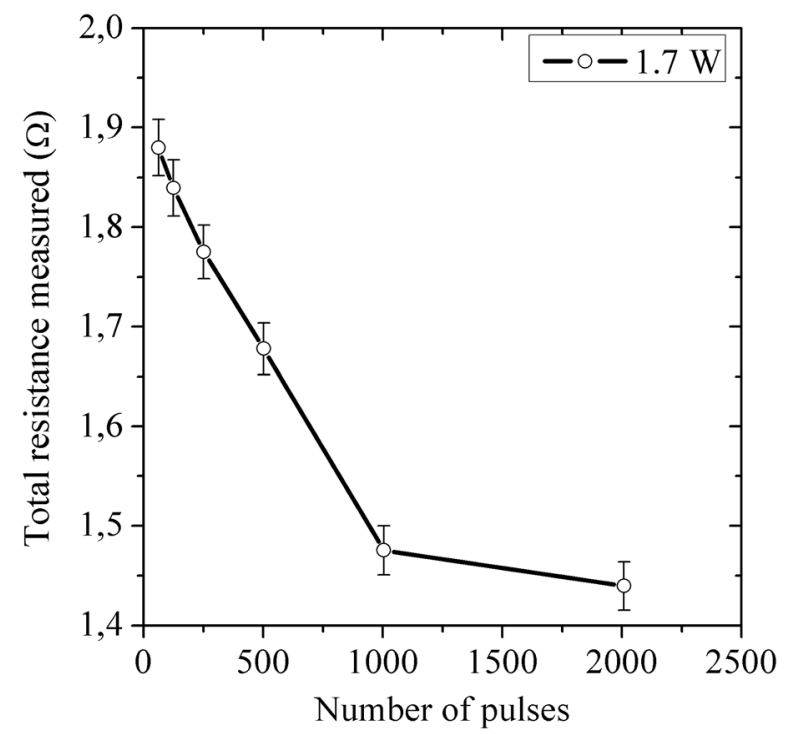

FIG. 8. Total resistance measured as a function of the $\mathrm{Np}$ parameter for $1.7 \mathrm{~W}$. 


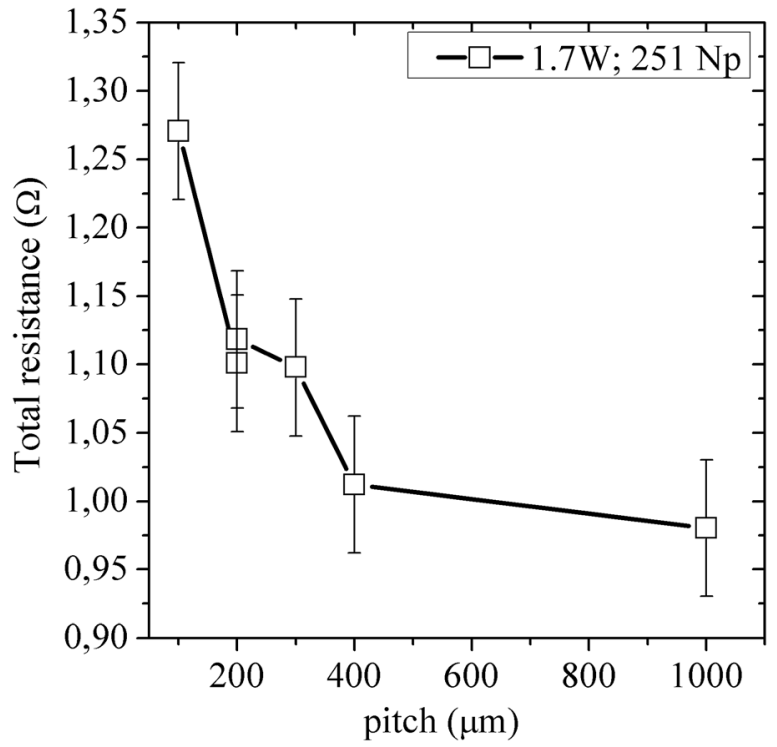

FIG. 9. Influence of the pitch parameter on the total resistance measured for $1.7 \mathrm{~W}$ and $251 \mathrm{~Np}$.

influence area of the LFC point is larger than the morphological evidence represented by the crater, as discussed in previous sections.

The pitch study was carried out using two LFC points on the same front round contact. In theory, two LFC points should act like two parallel resistances, so the total resistance should be half. This is true as long as the LFC areas do not overlap. Figure 9 shows how the pitch influences the total resistance measured for $1.7 \mathrm{~W}$ and $\mathrm{Np}=251$ pulses. The total resistance decreases as the pitch increases. This trend indicates that as the distance between two LFC points is increased, the area of LFC overlap is reduced. From Fig. 9, it can be concluded that pitch values greater than $400 \mu \mathrm{m}$ do not imply an effective reduction of the total resistance

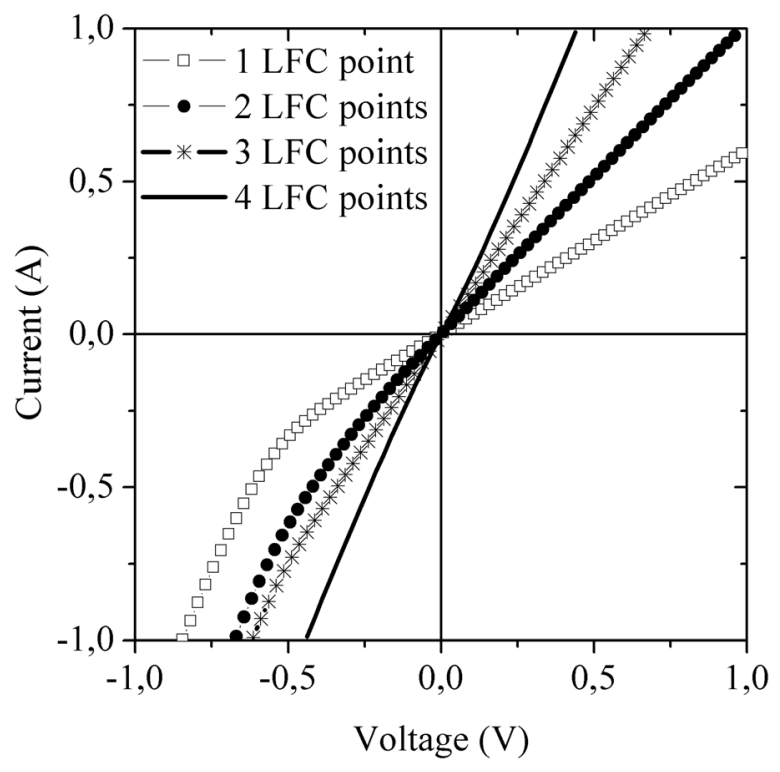

FIG. 10. I-V responses depending on the number of LFC points on the same front round contact using $1.7 \mathrm{~W}$ and $251 \mathrm{~Np}$. measured. Therefore, it can be concluded that the radius of the effective contact area is $200 \pm 10 \mu \mathrm{m}$, which is 3.2 greater than the radius of the measured crater (Fig. 7) for $1.7 \mathrm{~W}$ and $\mathrm{Np}=251$ pulses. If Eq. (6) is applied using this effective contact area and the $R_{\text {measured }}$ shown in Fig. 8, then the value obtained for the $\rho_{\text {cef } L F C}$ is $1.5^{*} 10^{-4} \Omega \mathrm{cm}^{2}$ for $1.7 \mathrm{~W}$ and $\mathrm{Np}=251$ pulses. The LFC area depends on both the laser power and the Np value. The LFC area depends on both the laser power and the $\mathrm{Np}$ value.

The final experiment consisted of increasing the number of LFC points on the same top contact with a pitch of $600 \mu \mathrm{m}$. Figure 10 shows the change in the structures I-V characteristics when the number of LFC points increases. This result verifies the equivalent electric circuit proposed in Fig. 4(b). Although this study reinforces the difficulty in determining the contact area, it demonstrates that using four LFC points causes the total resistance measured to be less than double the contact resistance of a $1.25 \mathrm{~mm}$ radius pad formed using the conventional process with a RTA step, which means a specific contact resistivity less than $2 * 10^{-4} \Omega \mathrm{cm}^{2}$.

\section{CONCLUSIONS}

A novel approach is used to form ohmic contacts on moderately p-doped GaAs substrates. The process avoids thermal stress to the whole structure associated with typical annealing steps. The ohmic contacts are fabricated by sputtering an $\mathrm{Au} / \mathrm{Zn} / \mathrm{Au}$ structure and using a laser-firing technique.

The influence of the RF sputtering power on $\mathrm{Zn}$ layer deposition was analyzed. Results do not show a relevant impact of this parameter on the rectifier behavior of the metal-semiconductor contact.

In laser-firing study, we explored the influence of different parameters on the electrical response and morphology of the resulting crater. A minimum laser power of $1.7 \mathrm{~W}$ is necessary in our system to produce $\mathrm{Zn}$ diffusion into the GaAs and create the tunneling contact. A study of the influence of $\mathrm{Np}$ (number of pulses) revealed that the area of influence is larger than the crater. This effect is substantiated by SEM images and EDX analysis.

A study of pitch led us to conclude that the radius of the effective contact area can be 3.2 greater than the crater radius. This study shows that using four LFC points on the same front round contact allowed us to achieve a specific contact resistivity less than $2 * 10^{-4} \Omega \mathrm{cm}^{2}$.

\section{ACKNOWLEDGMENTS}

This work was partially supported by The Spanish Ministry of Education and Science under the Consolider Ingenio 2010 Program, through the project GENESIS-FV (CSD2006-0004). Thanks to Trifon Trifonov for the SEM images and EDX analysis.

${ }^{1}$ V. L. Rideout, Solid State Electron. 18, 541 (1975).

${ }^{2}$ T. C. Shen, G. B. Gao, and H. Morkoç, J. Vac. Sci. Technol. B 10, 2113 (1992).

${ }^{3}$ A. G. Baca, F. Ren, J. C. Zolper, R. D. Briggs, and S. J. Pearton, Thin Solid Films 308-309, 599 (1997). 
${ }^{4}$ Yicheng Lu, T. S. Kalkur, and C. A. Paz de Araujo, J. Electrochem. Soc. 136, 3123 (1989).

${ }^{5}$ T. Sanada and O. Wada, Jpn. J. Appl. Phys. 19, L491 (1980).

${ }^{6}$ F. Ren, C. R. Abernathy, S. J. Pearton, and J. R. Lothian, J. Vac. Sci. Technol. B 13, 293 (1995).

${ }^{7}$ H. Cotal, C. Fetzer, J. Boisvert, G. Kinsey, R. King, P. Hebert, H. Yoon, and N. Karam, Energy Environ. Sci. 2, 174 (2009).

${ }^{8}$ G. J. Bauhuis, P. Mulder, E. J. Haverkamp, J. C. C. M. Huijben, and J. J. Schermer. Sol. Energy Mater. Sol. C 93, 1488 (2009).

${ }^{9}$ P. G. Linares et al., Sol. Energy Mater. Sol. C 108, 175 (2013).

${ }^{10}$ O. Moutanabbir and U. Gösele, Annu. Rev. Mater. Res. 40, 469 (2010).
${ }^{11}$ P. Ortega, A. Orpella, I. Martín, M. Colina, G. López, C. Voz, M. I. Sánchez, C. Molpeceres, and R. Alcubilla, Prog. Photovolt: Res. Appl. 20, 173 (2012).

${ }^{12}$ W. Brendle, V. X. Nguyen, A. Grohe, E. Schneiderlöchner, U. Rau, G. Palfinger, and J. H. Werner, Prog. Photovolt: Res. Appl. 14, 653 (2006).

${ }^{13}$ I. Sánchez-Aniorte, R. Barrio, A. Casado, M. Morales, J. Cárabe, J. J. Gandía, and C. Molpeceres, Appl. Surf. Sci. 258, 9443 (2012).

${ }^{14}$ K. Wasa and S. Kayakawa, Handbook of Sputter Deposition Technology (Noyes Publications, NJ, 1992), 64 pp.

${ }^{15}$ M. W. Denhoff, J. Phys D: Appl. Phys. 39, 1761 (2006). 